\title{
THE EFFECT OF EMBANKMENT CREST WIDTH ON COMBINED OVERFLOW AND WAVE OVERTOPPING
}

\author{
David K. Jones ${ }^{1}$, Dominic E. Reeve ${ }^{2}$, Qingping Zou \\ In this paper a Reynolds-averaged Navier-Stokes based wave model (RANS) has been used to investigate how the \\ discharge caused by combined overflow and wave overtopping of embankments is influenced by embankment crest \\ width. The results demonstrate that embankments with a narrower crest width can expect significantly increased \\ discharge in accordance with that expected for flow over weirs. The experimental results have been used to explain \\ the difference in discharge found with the current design formulae for combined overflow and wave overtopping.
}

Keywords: wave overtopping; overflow; embankments; levees; dikes

\section{INTRODUCTION}

In many low-lying areas of the world, protection from coastal flooding is provided by embankments, levees and dikes. In extreme cases, combinations of high tides, waves, wave set-up and storm surges driven by wind set-up and low-pressure weather systems can cause water levels to rising above the level of the embankment crest. When the water level is above the embankment crest, this is termed negative freeboard, $R_{c}$, and when this is combined with wave overtopping this is called combined discharge. These terms are clarified in Fig. 1. The effect of sea level rise and increased storminess due to global warming is likely to result in more extreme waves and storm surges and this will increase the likelihood of combined discharge. This can create a dangerous situation caused by the volume of water flowing over the crest but there is also the potential for combined discharge to remove lee side protection, erode the back face and possibly breach the embankment.

This paper considers how combined discharge is reduced when embankment crest width is increased. The current design formulae for combined discharge are investigated to determine if the different embankment crest widths used in their empirical derivation could account for differences in combined discharge predicted with these formulae.
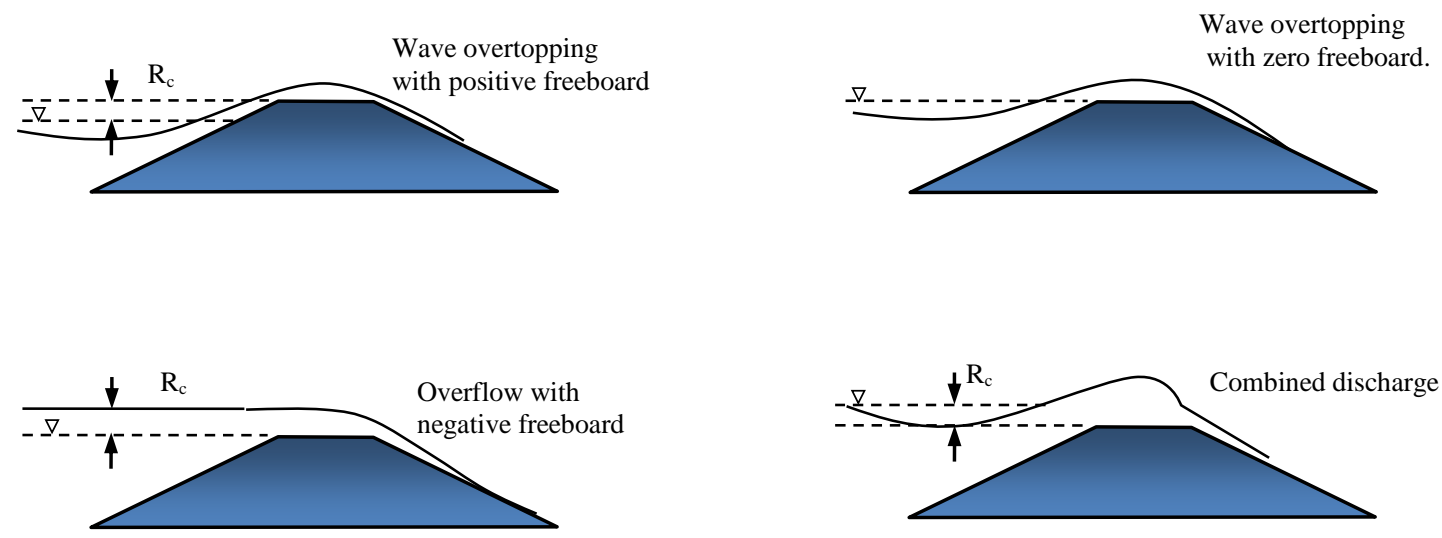

Figure 1. Overtopping of embankments.

\section{Current Empirical Formulae}

Although researchers have widely investigated wave overtopping of embankments with positive freeboard, see Hedges and Reis (1998), combined discharge has attracted much less attention. The current design formulae used to determine combined discharge are given in Pullen et al. (2007), Reeve et al. (2008) and Hughes and Nadal (2009).

Of the three different design formulae available to determine overtopping discharge for combined discharge, perhaps the simplest approach was taken in the EurOtop manual, Pullen et al. (2007). This splits combined discharge into its two elements, the wave component and the overflow component. The

\footnotetext{
${ }^{1}$ Britannia Royal Naval College, Dartmouth, Devon, UK

2 Department of Civil and Environmental Engineering, University of Maine, Orono, ME, USA

${ }^{3}$ Coastal Engineering Research Group, College of Engineering, Swansea University, Swansea, UK
} 
wave component $q_{\text {waves }}$ can be found using the equation for discharge over embankments with zero freeboard developed by Schüttrumpf (2001), given in Equations (1) for random waves.

$$
\begin{gathered}
\frac{q_{\text {waves }}}{\sqrt{2 g H_{s}^{3}}}=0.038 \xi_{\text {om }} \text { for } \xi_{\text {om }}<2 \\
\frac{q_{\text {waves }}}{\sqrt{2 g H_{s}^{3}}}=0.096-\frac{0.160}{\xi_{\text {om }}{ }^{3}} \text { for } \xi_{\text {om }}>2
\end{gathered}
$$

and

where $\xi$ is the Iribarren number, and $H_{s}$ is the significant wave height. The overflow part of the discharge, $q_{\text {weir }}$, can be calculated by assuming the embankment would behave similarly to a broad crested weir. This can be found from ISO 3846:2008 which is the international standard for flow over broad crested weirs. The equation given in the standard is equivalent to Equation (2),

$$
q_{\text {weir }}=C_{d} \times 1.705 b h_{u}^{3 / 2}
$$

where $\mathrm{b}$ is the weir breadth and $h_{u}$ is the upstream depth above the crest. Ackers et al. (1978) gives $C_{d}$ as 1.0 for ideal fluids. For real fluids ISO 3846:2008 gives tables and graphs that allow $C_{d}$ to be evaluated, with $C_{d}$ being dependent on the ratios of the upstream head to crest width and upstream head to height of weir. However, ISO 3846:2008 only gives values of $C_{d}$ for weirs with vertical edges, for embankments with sloping faces suitable values of $C_{d}$ need to be found by experimental methods. An estimate of the combined discharge is given by the superposition of the overflow component and the wave component. This method is unlikely to fully account for the complex hydrodynamic flow conditions that occur at the embankment crest during combined discharge but was the first methodology that attempted to determine combine discharge. Alternative formulae for calculating combined discharge, $q$, were developed by Reeve et al. (2008) and are given in Equations (3). These are based on the functional form of the equation given in van der Meer (1995) for wave overtopping with positive freeboard. However, Equations 3 were based on a series of numerical flume tests of wave overtopping on a seawall subjected to negative freeboard and used the Reynolds-averaged NavierStokes (RANS) based wave model developed by Lin and Liu (1998). The equations are based on regression analysis of the numerical flume tests for irregular breaking and non-breaking waves on seawalls with slopes 1:3,1:4 and 1:6 and small negative dimensionless freeboards $\left(R=R_{c} / H_{s}\right)$ in the region $0.0>R \geq-1.0$.

$$
\begin{array}{ll}
\frac{q}{\sqrt{g \cdot H_{s}^{3}}} \cdot \frac{\sqrt{\tan \alpha}}{\xi_{p}}=0.051 \exp \left(-1.98 \frac{R_{c}}{H_{s} \xi_{p}}\right) & \text { for } \xi_{p}<2.0 \\
\frac{q}{\sqrt{g \cdot H_{s}^{3}}}=0.233 \exp \left(-1.29 \frac{R_{c}}{H_{s}}\right) & \text { for } \xi_{p} \geq 2.0
\end{array}
$$

A further equation for combined discharge was developed by Hughes and Nadal (2009) based on a series of laboratory experiments of combined discharge over embankments. These physical model tests were conducted at a scale 1:25 for irregular breaking and non-breaking waves on a seawall slope of 1:4.25. The negative freeboards tested were $0.29,0.81$ and $1.3 \mathrm{~m}$. A regression analysis of physical model test data gave Equation (4), where $H_{m 0}$ is the energy based significant wave height.

$$
\frac{q}{\sqrt{g \cdot H_{m 0}^{3}}}=0.034+0.53\left(\frac{-R_{c}}{H_{m 0}}\right)^{1.58} \quad \text { for } R_{c}<0
$$

Of these current equations, none considers the effect of crest width on reducing the overall overtopping discharge.

For this study the combined discharge found with these formulae were compared. The combined discharge was determined for a range of wave conditions, differing negative freeboards and a 1:4.25 seaward slope was used in Equation (3). The results are plotted in Fig. 2. It should be noted that the data points for the equations given for Reeve et al. are only plotted within the range of applicability of the equation. The figure shows that there is some variation in combined discharge determined with the current design formulae. The formula given by Hughes and Nadal (2009) predict the lowest discharge and Reeve et al. (2008) predict the greatest combined discharge. 


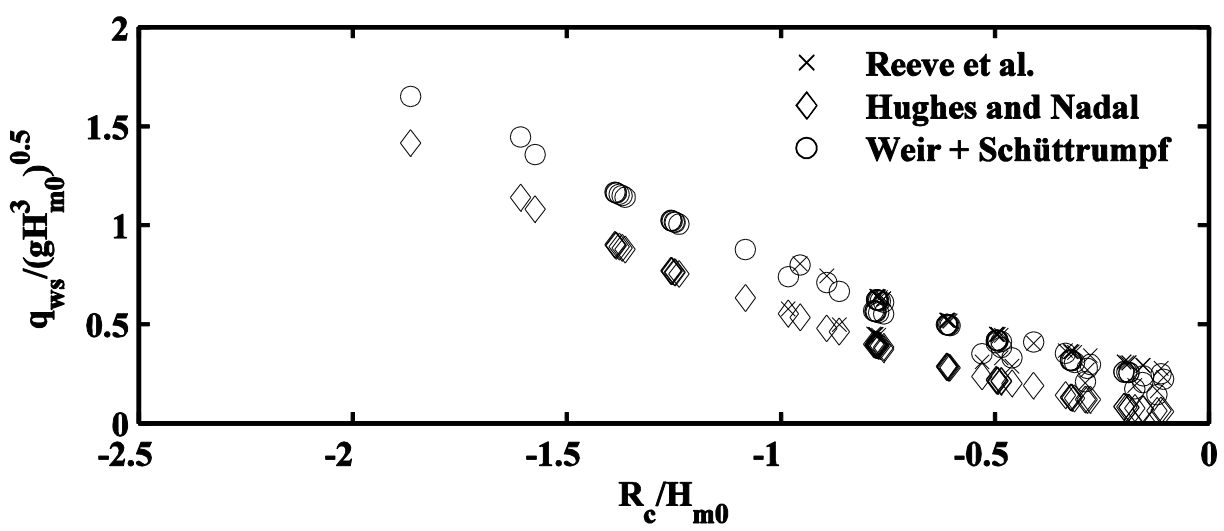

Figure 2. Dimensionless combined discharge and dimensionless negative freeboard for the current design formulae.

However, these equations were empirically derived for different embankment configurations. Possibly the most significant difference between the embankments tested was the width of the embankment crests. The Hughes and Nadal formula used a $3.05 \mathrm{~m}$ embankment crest width for the physical model tests, whilst the tests conducted in a numerical flume by Reeve et al. used a sea wall with a sloping seaward gradient and only a narrow crest of approximately $0.5 \mathrm{~m}$. The crest of this wall would act more like a sharp edged weir than a broad crested weir. The discharge over a rectangular sharp edged weir is given by Douglas (1979) as;

$$
q_{\text {weir }}=\frac{2}{3} b \sqrt{(2 g)} h^{3 / 2}
$$

where $\mathrm{h}$ is the depth at the weir. A comparison between Equation (5) and Equation (2) shows that a thin plate weir would be expected to show an increase in measured discharge. If the wider embankment crest behaved similarly to a broad crested wear and the narrower crest behaved more like a sharp edged weir then this could account for the differences found in the formulae given by Reeve et al. and Hughes and Nadal.

\section{Numerical Model Study}

In this study a RANS model has been used to investigate the effect of embankment crest width upon the combined discharge over embankments. The RANS model can calculate the free surface and general turbulent flow under waves. The wave surface profile is tracked using the volume of fluid method (VOF). This method was originally developed by Hirt and Nichols (1981) and later modified by Kothe et al. (1991). For these tests, the RANS model used a second-order $k$ - $\varepsilon$ turbulence closure model, where $k$ is the turbulent kinetic energy and $\varepsilon$ is the turbulence dissipation. A fuller description of the model can be found in Lin and Liu (1998). The RANS model used in this study is the same model used by Reeve et al. (2008).

The version of the model used for these tests contain wave generation and efficiency modifications by Torres-Freyermuth (2007). The wave generation uses a wave time history defined at the seaward boundary. This is sometimes used in preference to a source function, (e.g. Lin \& Liu 1999), because the absorbing sponge layer is not required at the wave generating boundary and leads to a more efficient reduction in computational domain. The wave generating procedure assumes that the high frequency energy is dissipated by the breaking waves at the embankment and the long wave components reflected from the shore propagate as non-dispersive waves according to linear shallow water wave theory. At the wave generating boundary, linear superposition between incident and reflected waves is used. The wave generation procedure also requires the velocity components at the boundary, these are derived from the wave height data using linear theory.

To ensure conservation of mass within the numerical flume the wave overtopping discharge must be recycled back into the flume. Failure to do this would result in a lowering of water level within the flume over time. In the model this was achieved by firstly determining the discharge from the depth and velocity information at the crest of the embankment. This was then used as an input back into the model as a depth averaged velocity at the seaward boundary. This velocity was combined with the velocity determined for wave generation at the boundary. However, if the instantaneous discharge was directly fed back into the computational regime, it generates a false wave at the boundary. This problem was overcome by using a running average of the required velocity at the boundary. A running 
mean over a twenty second period successfully produced the required wave profiles whilst maintaining the water level in the numerical flume.

\section{Model Tests}

In a previous study by Jones et al. (2010), this numerical model was validated for combined discharge by simulating the physical model test conducted by Hughes and Nadal (2009). The tests demonstrated that the numerical model could successfully predict, on a wave by wave basis, the combined discharge over embankments. In the current study the configuration of the 2D numerical flume was also similar to that used in the physical model study conducted by Hughes and Nadal (2009). However, the crest widths vary from $0.5 \mathrm{~m}$ to $3.05 \mathrm{~m}$ in $0.5 \mathrm{~m}$ increments. In all, 74 random wave tests were conducted and include negative freeboards between $-0.1 \mathrm{~m}$ and $-1.6 \mathrm{~m}, H_{s}$ in the range 0.26 to $2.71 \mathrm{~m}$, Rc between 0.26 and $1.21 \mathrm{~m}$, Tp between 5.7 and $14.6 \mathrm{~s}$ and $\xi$ between 1.1 and 5.1. The cross-section of the embankment in the numerical model is shown in Fig. 3.

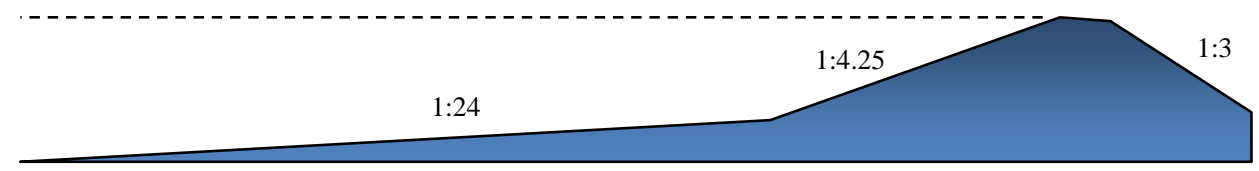

|

Figure 3. Detail of the numerical model embankment cross section.

The wave generating boundary of the numerical model was located $210 \mathrm{~m}$ from the embankment crest. The landward boundary of the numerical model was defined on the 1:3 lee side slope of the embankment. This boundary was defined as being an open boundary, so allowing waves to exit the flume without reflection. This lets waves partially reflected from the sloping front face of the embankment structure to leave the computational domain. Fig. 4 shows the extent of the numerical model.

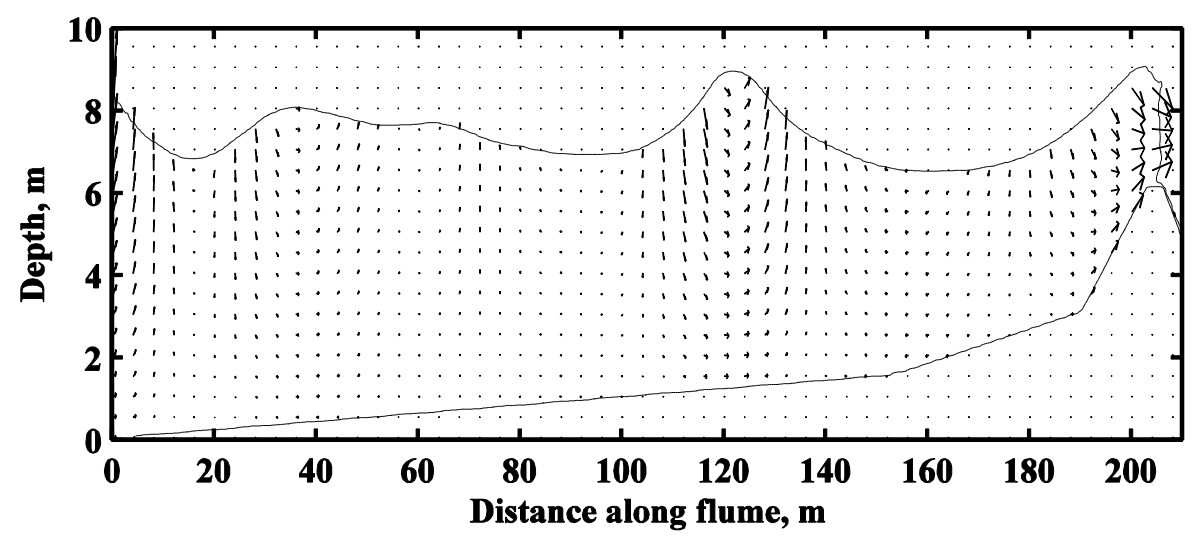

Fig. 4 A snap shot showing wave surface elevation, embankment detail and flow field velocity vectors plotted at every fifth node vertically and every tenth node horizontally

The maximum node spacing for the computational mesh was $0.4 \mathrm{~m}$ horizontally and $0.1 \mathrm{~m}$ vertically. However, for some tests the mesh size had to be reduced to adequately define flow during wave breaking but also to resolve the flow on the landward side of the embankment. This was often intermittent, relatively shallow and fast flowing. The minimum node spacing used for the mesh was $0.1 \mathrm{~m}$ horizontally and $0.05 \mathrm{~m}$ vertically. Similarly, the time step varied between $0.01 \mathrm{~s}$ and $0.002 \mathrm{~s}$.

The duration of the RANS-VOF model tests was 250s. The initial period of the tests began with a period of steady overflow with no waves. During this period the embankment behaved like a weir and this allowed the upstream head to be determined in accordance with ISO 3846:2008 which states that the head should be recorded at a location approximately 3.5 times the nominal upstream head from the seaward edge of the embankment. The upstream head at this location was considered to be equivalent to the negative freeboard. 


\section{Results}

An initial series of tests were conducted with the same wave condition but with six different crest widths and five negative freeboards. The tests used a $1.53 \mathrm{~m} H_{s}$ and $14.4 \mathrm{~s} T_{p}$ and $R_{c}$ between $-0.289 \mathrm{~m}$ to $-1.175 \mathrm{~m}$. Fig. 6 shows how the combined discharge varies with embankment crest width for this series of tests. The figure demonstrates that as the crest width is increased, a corresponding reduction in combined discharge was found. This was observed for each of the negative freeboards tested. The shorter crest width increases discharge by an average of $21 \%$ compared to the wider crest width.

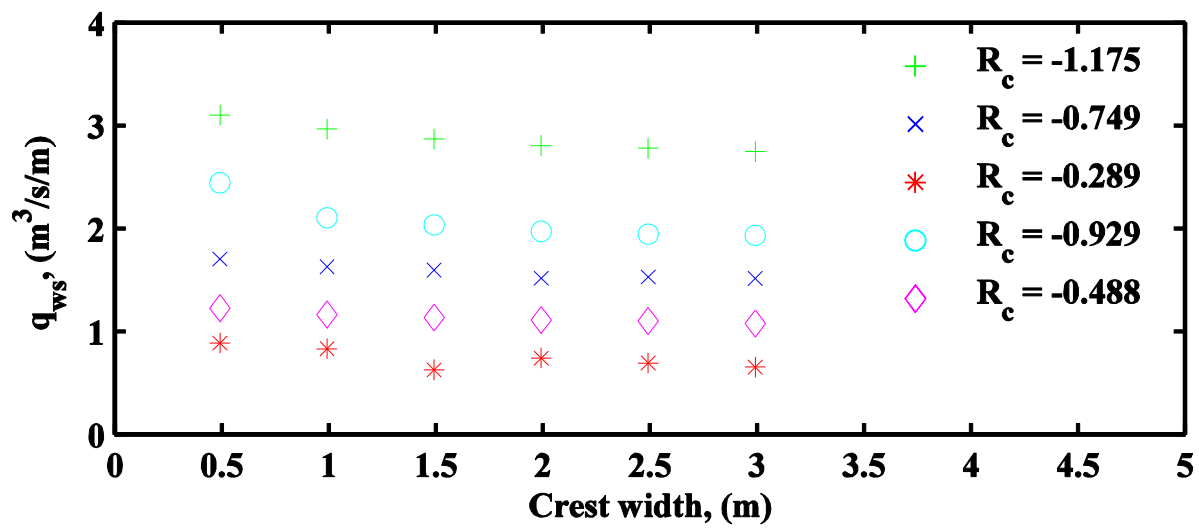

Figure 6. Combined discharge and crest width for five values of negative freeboard, $\boldsymbol{R}_{c}$.

For the same tests it is useful to plot the dimensionless discharge against the dimensionless negative freeboard. This can then be compared with the dimensionless discharge and dimensionless negative freeboard determined from Pullen et al. (2007), Reeve et al. (2008) and Hughes and Nadal (2009), as shown in Fig. 7. This shows that the combined discharge determined from Reeve et al. and Pullen et al. have higher discharge than that found with Hughes and NHadal, with the results from the RANS model falling between the higher and lower values. The vertical spread in the combined discharge determined with the RANS model results from the variation in discharge with embankment crest width. With the higher values of combined discharge resulting from the tests with the shorter crest width. As Equations (3) were derived from tests with a $0.5 \mathrm{~m}$ crest width, while Equation (4) was derived from tests with a $3.05 \mathrm{~m}$ crest width and the RANS model tests include crest widths varying between $0.5 \mathrm{~m}$ to $3.05 \mathrm{~m}$, the RANS model results should range between the results found with Equations (3) and Equation (4). Fig. 7 demonstrates that the RANS model data range between these results but, other factors must also influence the results. Another possible other influencing factor between Equations (3) and (4) may be that Equations (3) was derived from tests with a vertical leeside slope, whereas, Equation (4) was derived from tests with a 1:3 lee side embankment slope. The configuration with the vertical landward side to the embankment crest would be expected to have a greater discharge and this explanation is consistent with the results observed.

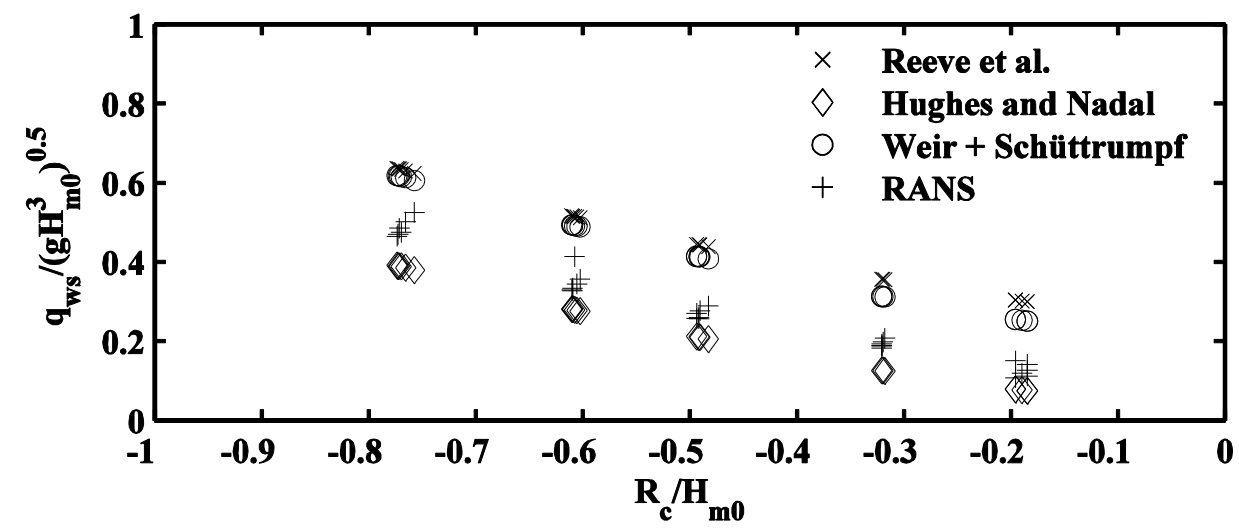

Figure 7. Dimensionless combined discharge and dimensionless negative freeboard for crest width between 0.5 and $3.0 \mathrm{~m}$ determined with the current design formula and the RANS model. 
Existing formulae for combined discharge do not include a term for embankment crest width and it may be expected that the combined discharge would be the same for each crest width. However, for each negative freeboard, a small degree of spread in the combined discharge determined with these equations can be seen in Fig. 7. This is because, for the test with narrower crest width, the drawdown that occurs near weirs will extend further seaward from the embankment crest. As a consequence, even though the water level remained the same, the determined negative freeboard for narrower crest widths would be slightly lower, and the lower negative freeboard results in marginally lower values of the calculated combined discharge.

\section{Conclusion}

In this study, the discharge rates for combined discharge over an embankment calculated with the RANS model were compared with three available design formulae. The dimensionless discharge calculated with the equation given by Hughes and Nadal (2009) was found to be less than that found with the method suggested by Pullen (2007), and the highest discharge was found with the equation given by Reeve et al. (2008). However, the experimental set-up used by Reeve et al. was based on a seawall configuration with a sloping seaward face retained by a thin wall whilst the physical model setup used by Hughes and Nadal used an embankment with a broad crest and sloping sides. A comparison between the discharges determined with these formulae show that the equation given by Reeve et al. gives the greatest discharge and that given by Hughes and Nadal give the lowest values.

This study has used the RANS model to investigate the effect of crest width on the rate of combined discharge over embankments, with view to explaining the differences in the current design formulae for combined discharge. The model was used to conduct a series of tests with the same embankment configuration but with crest widths increasing from $0.5 \mathrm{~m}$ to $3.05 \mathrm{~m}$. A number negative freeboards and random wave conditions were tested and in all 74 tests were conducted. The combined discharge was found to decrease as the embankment crest increased. Reducing the embankment crest width from $3.05 \mathrm{~m}$ to $0.5 \mathrm{~m}$ resulted in an average $21 \%$ increase in combined discharge. It was found that the effect of a narrower crest width did, to a large degree, account for the differences between the equation given by Reeve et al. (2008) and that given by Hughes and Nadal (2009). However, remaining differences may be accounted for by other factors such as the details of the lee slope.

The current design equations for combined discharge considered in this paper do not include embankment crest width. However, this study has demonstrated that combine discharge does vary with embankment crest width and so, inclusion of a crest width term in a design formula is likely to improve results. The results from this work are currently being used to develop an equation for combined discharge that includes a term for combined discharge.

Further work should consider the effect on combined discharge of the embankment lee side and seaward slope, berm, and water depth at the toe of the structure. These should be tested for a range of wave conditions and the results should then be formulated into design advice.

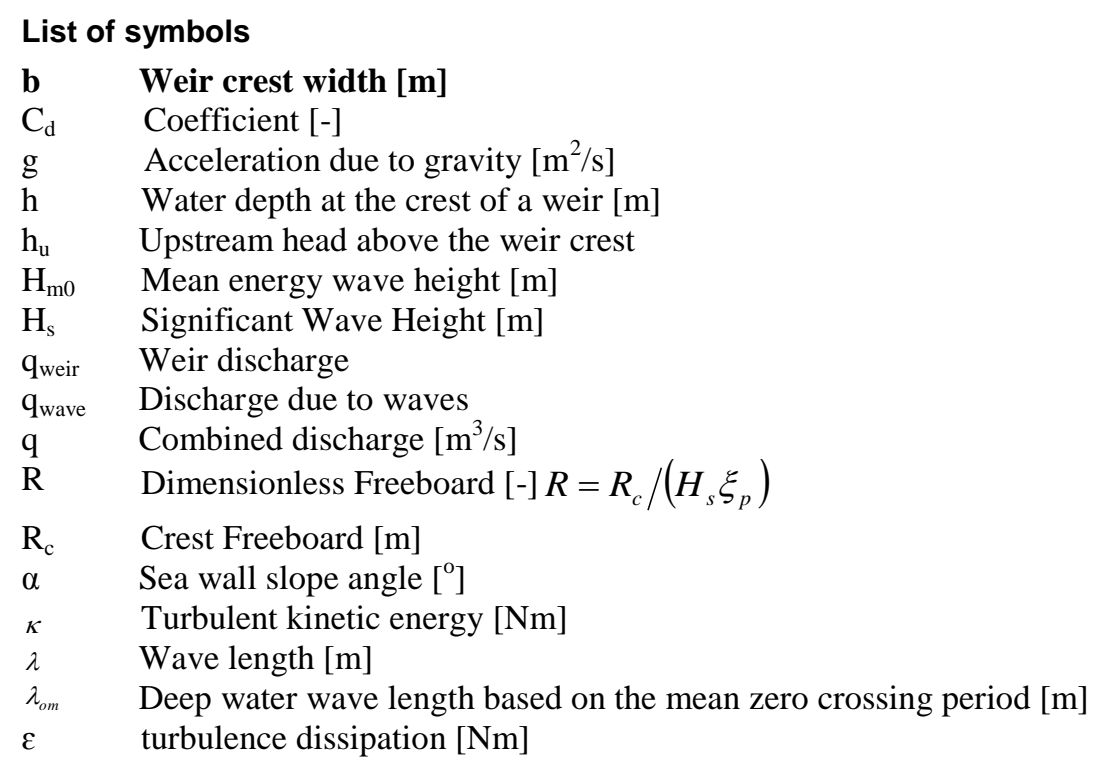


$\xi_{\text {om }} \quad$ Iribarren number defined as $\xi_{\text {om }}=\frac{\tan \alpha}{\sqrt{H_{m 0 /} \lambda_{o m}}}$
$\xi \quad$ Surf similarity parameter (Iribarren number) defined as $\xi=\frac{\tan \alpha}{\sqrt{H_{s /}, \lambda}}$

Other symbols are defined in the text

\section{REFERENCES}

Ackers P., White W.R., Perkins J.A. \& Harrison A.J.M. Weirs and Flumes for flow Measurement. Chichester: Wiley, 1978.

Douglas, J. F., Gasiorek J. M., Swaffield J. A., 1979. Fluid Mechanics. Pitman. London.

Hedges, T. S., Reis M. T., 1998. Random wave overtopping of simple sea walls: a new regression model. Proc. ICE: Water, Maritime and Energy. Vol. 130 - 1: pp. 1-10.

Hughes, S.A.,Nadal, N.C.,2009. Laboratory study of combined wave overtopping and storm surge overf low of a levee. Coastal Engineering, vol. 56. pp. 244-259.

Hirt, C. W., Nichols, B. D., 1981. Volume of fluid (VOF) method for dynamics of free boundaries. J Comput. Phys. 39, pp. 201-225.

ISO 2008, Hydrometry. Open channel flow measurement using rectangular broad crested weirs. ISO 3846:2008, ISO.

Jones, D. K., Zou Q., Reeve D. E, 2012. Computational modelling of coastal flooding caused by combined surge overflow and wave overtopping on embankments. J Flood Risk Management, DOI: 10.1111/j.1753-318X.2012.01155.x

Kothe, D.B., Mjolsness, R.C., Torrey, M.D., 1991. RIPPLE: a computer program for incompressible flows with free surfaces. Report LA-12007-MS, Los Alamos Scientific Report, Los Alamos, NM, USA Lin, P., Liu, P.L.-F., 1998. A numerical study of breaking waves in the surf zone. Journal of Fluid Mechanics 359. pp. 239-264.

Lin P. \& Liu P.L.-F. 1999. Internal wave-maker for Navier-Stokes equations models. J Wtrwy Port Coastal Ocean Eng, 125, (4), 207-215.

Pullen T., Allsop N.W.H., Bruce T., Kortenhaus A., Schüttrumpf H. \& van der Meer J.W. 2007. EurOtop: wave overtopping of sea defenses and related structures: assessment manual. http://www.overtopping-manual.com/manual.html

Reeve, D.E., Soliman, A., Lin, P.Z., 2008. Numerical study of combined overflow and wave overtopping over a smooth impermeable seawall. Coastal Engineering, vol. 55. pp. 155-166.

Schüttrumpf, H. 2001. Wellenüberlaufströmung bei Seedeichen - Experimentelle und Theoretische Untersuchungen. PhD-Thesis.

Torres-Freyermuth, 2007. Estudio de la Hidrodińamica de la Zona de Rompientes mediante ecuaciones tipo RANS, PhD-Thesis.

van der Meer, J. W., Janssen J. P.F.M., 1995. Wave run-up and wave overtopping at dikes. In: Wave Forces on Inclined and vertical wall structures. American Society of Civil Engineers. pp. 1-27 